

\title{
Imágenes y Perspectivas Sobre la Maternidad en las Estudiantes de la Universidad Nacional de Santiago del Estero
}

\author{
Imagens e Perspectivas Sobre a Maternidade das Estudantes da \\ Universidad Nacional de Santiago del Estero
}

\author{
Female Student's Images and Perspectives about Motherhood at Universidad \\ Nacional de Santiago del Estero
}

\begin{abstract}
Resumen
El presente artículo se propone reflexionar desde una metodología interpretativa, acerca de las imágenes y perspectivas que tienen las estudiantes universitarias respecto de la maternidad y sus implicancias en relación a la articulación entre sus proyectos académicos y la vida familiar intentando comprender sus realidades. Esta investigación ha demostrado que si bien las representaciones de las estudiantes en general están estrechamente ligadas a sus planes académicos laborales y en correlación con sus aspiraciones de vida en un sentido más amplio; las concepciones que tienen sobre ser madres están fuertemente marcadas por los mandatos establecidos tradicionalmente. A pesar de ello, los nuevos escenarios sociales han favorecido de manera significativa las posibilidades de autorrealización de las mujeres en los espacios universitarios.
\end{abstract}

Palabras-Clave: Maternidad; Universidad; Proyecto Académico; Espacio Doméstico.

\section{Resumo}

Este artigo tem como objetivo refletir a partir de uma metodologia interpretativa, sobre as imagens e as perspectivas que tem as estudantes universitários sobre a maternidade e suas implicações em relação la articulacão entre seus projectos acadêmicos e a vida familiar tentando entender suas realidades. Esta pesquisa mostrou que, embora as representações das estudantes em geral estão intimamente ligadas a seus planos acadêmicos de trabalho e em correlação com suas aspirações de vida em um sentido mais amplo; as concepções que têm sobre ser mães estão fortemente marcadas pelos mandatos estabelecidos tradicionalmente. No entanto, os novos cenários sociais favoreceu significativamente as possibilidades de autorealização das mulheres nos espaços universitários.

Palavras-Chave: Maternidade; Universidade; Projeto Acadêmico; Espaço Doméstico.

\begin{abstract}
This article proposes a reflection, according to an interpretive methodology, about images and perspectives of university female students about motherhood and its implications linked with the articulation among academic projects and familiar life, seeking to understand their realities. This research has shown that although in general female student's representations are closely linked with their academic and professional projects as related to their aspirations in life, in a broadest sense, their ideas about being mothers are strongly marked by traditionally established social impositions. Nevertheless, the new social sceneries significantly favored the possibilities of women's self-fulfilment in academic spaces.
\end{abstract}

Keywords: Motherhood; University; Academic Project; Domestic Space.

Noelia Noemi Aranda 
Las percepciones y significaciones sobre la maternidad han sufrido cambios durante los últimos años y esto puede considerarse el resultado de varios procesos entre los cuales se encuentra el ingreso de las mujeres a los ámbitos universitarios, como un elemento importante al interior de procesos sociales más amplios. A razón de ello, las mujeres y sobre todo las más jóvenes comenzaron a experimentar una creciente individualización y autonomía, que ha contribuido en debilitar de alguna manera al poder patriarcal otorgando en algunos casos mayor independencia.

El desarrollo de nuevas formas de organización social en donde las mujeres pasaron a configurar papeles que exceden los límites de lo doméstico y lo privado, posibilitando que su rol como unidad productiva dentro de la familia deje de ser fundamental; abrió un abanico de posibilidades para la diversificación de los roles que tradicionalmente venía desarrollando. Estas recientes configuraciones han contribuido por un lado a disminuir el deseo de 'ser madres' en algunas mujeres como una forma de autoafirmarse y realizarse de manera personal, mientras que para otras la maternidad continúa siendo un modo de completarse ligado estrechamente con un hecho natural y biológico.

Dentro de este marco general, el presente trabajo pretende responderse a algunos cuestionamientos que surgieron como pequeñas inquietudes al momento de comenzar la investigación y que a partir de la experiencia de campo tomaron forma y a veces fueron mutando por otras nuevas. Resulta interesante para nuestro estudio entonces, conocer cuáles son las imágenes y perspectivas que tienen las estudiantes sobre la maternidad y sus implicancias respecto de la articulación entre sus proyectos académicos y la vida familiar. Así como también, la manera en qué afecta o no sus expectativas de autorrealización profesional y laboral, exponiendo diversos aspectos relativos a las percepciones que tienen sobre los obstáculos que pudieron o pueden ocasionarles el hecho de ser madres.

La intención metodológica en este trabajo es de tipo interpretativa y por su naturaleza misma cualitativa ya que a partir de las reflexiones personales de las estudiantes se intentará comprender y analizar sus realidades, tratando de establecer comparaciones y descripciones relacionadas con las percepciones y perspectivas que tienen respecto de la maternidad.

Se presentarán aquí los resultados obtenidos mediante entrevistas en profundidad realizadas a un grupo de 8 estudiantes de distintas carreras pertenecientes a la Universidad Nacional de Santiago del Estero (en adelante UNSE). Las entrevistadas fueron escogidas a partir de una muestra aleatoria tomando como criterios de selección las siguientes características: a) que se encuentren cursando actualmente alguna carrera de grado dentro de la Universidad, b) que no superen los 28 años de edad, c) que hayan atravesado o no por el proceso de maternidad y, d) que desempeñen algún trabajo formal o informal fuera del hogar.

De acuerdo a lo expresado en las conversaciones con las estudiantes se encontraron algunas imágenes y concepciones sobre la maternidad, que a veces difieren $y$ en otros casos no. Para una gran mayoría de ellas las representaciones que tienen del asunto están estrechamente ligadas a sus 
Imágenes y Perspectivas sobre la Maternidad en las Estudiantes de la

Universidad Nacional de Santiago del Estero

proyectos académicos laborales y en correlación con sus aspiraciones de vida en un sentido más amplio. Estas cuestiones intentarán describirse a lo largo del presente trabajo.

\section{Maternidad y Proyecto Académico: Sus Implicancias}

La maternidad siempre se presenta como un "nudo de conflictos" (MAFFIA, 2008, p. 7) el valor y la significación que se le asigna ocasiona ciertas dificultades o al menos se transforma en un asunto que es necesario pensar cuando se trata de considerar un proyecto académico que implique posteriormente el ejercicio del mismo.

Es importante mencionar algunos aspectos que han contribuido a modificar el prototipo histórico de la maternidad, autoras como (JELIN, 2012; NARI, 2004; LARGARDE, 1999 y VALLADARES , 1994) han analizado las influencias que tuvieron sobre esta cuestión la participación femenina en la fuerza de trabajo, el vínculo entre los niveles educativos alcanzados, la separación entre la sexualidad y la procreación que conlleva a nuevas formas de expresión de lo sexual y la conformación de la familia, el surgimiento y la difusión de los métodos anticonceptivos, entre otras cuestiones.

Sin duda que, el acceso de las mujeres a las universidades favoreció el desarrollo de nuevas políticas de inclusión, dando posibilidad a generar debates y controversias respecto de la capacidad que tenían para hacerlo. No sin tener que vencer algunos obstáculos, en los últimos años se ha visto diversificado la incorporación del sexo femenino a los estudios superiores; sin embargo las relaciones que suelen producirse dentro del ámbito universitario se encuentran fuertemente marcadas por los estereotipos de géneros fijados social y culturalmente. Al incorporarse al mundo universitario, las mujeres se enfrentan a condiciones distintas al momento de pensar en estudiar una carrera, ya que las habilidades en que han sido socializadas se relacionan con el ámbito de la vida privada (cooperación, cuidado, responsabilidad, afectividad) y se contraponen con las exigencias profesionales, que se asocian más a las habilidades masculinas (competencia, agresividad, neutralidad, desapego), requiriendo el desarrollo de roles contradictorios que en ocasiones influyen negativamente en sus proyectos académicos.

A mediados de los años cincuenta la participación de las mujeres en distintos terrenos caracterizados como públicos fue acrecentándose y cada día más mujeres trabajan fuera del hogar, son responsables económicamente de su núcleo familiar y buscan independizarse a través de la inclusión en espacios que se presentan como legitimadores de su realización personal ello fue resultado de un largo proceso según Valente (2008). Dicho proceso provocó una expansión de las mujeres a múltiples espacios, el académico, el estatal, el de la cultura, el de los medios de comunicación etc. Con lo cual han podido reingresar en esos espacios bajo nuevas condiciones, con nuevas herramientas e innovadores campos discursivos lo cual les deja a la mano un vasto territorio de acción y reflexión.

Para las mujeres ser madres constituye un hecho que según los patrones tradicionales de conducta las define como tales, según Valladares (1994) durante el transcurso de su socialización se les transmiten contenidos que de 
alguna manera refuerzan inconscientemente los mitos sobre la maternidad, conformando todo un discurso ideológico de cómo debería ser una madre y de esta manera condicionan la subjetividad de la mujer. Es entonces como de esta manera se socializa a las mujeres para que alcance en la maternidad la plenitud de su feminidad y la forma de vida más completa.

Dice Lagarde (1999, p. 365) "En el mundo patriarcal se especializa a las mujeres en la maternidad: la reproducción de la sociedad" La maternidad define a la mujer y por ello se encuentra presente en su mundo público y privado, al ser considerada y asociada como algo innato a ella supera las diferencias sociales, la preparación, los conocimientos académicos obtenidos o habilidades desarrolladas. Cuando las mujeres para concretar sus proyectos académicos deciden no renunciar a la maternidad, por lo general sus comportamientos no responden a los modelos de madres tradicionales.

En un análisis de Maffia (2008, p. 4 ) sobre las mujeres en la universidad y el ejercicio de la maternidad, dice que hay un enorme impacto en la subjetividad de ellas cuando al tratar de cumplir un doble mandato (esto es rol académico - rol profesional) se les requiere de capacidades contradictorias en los roles que pretende asumir, ya que desde la infancia son socializadas en actitudes de cooperación, intimidad y emocionalidad, mientras que al descubrir el mundo público de lo académico se da cuenta de que debe asumir actitudes de la subjetividad masculina (objetividad, neutralidad, desapego, etc.) para atravesar por él y alcanzar logros reconocidos.

\section{Desigualdades de Género en los Espacios Universitarios}

En las universidades todavía se encuentran presentes aquellos mecanismos que continúan favoreciendo la exclusión o deserción de las mujeres en dichos espacios y que de alguna manera obstaculizan la concreción y ejercicio de sus carreras. Entre las inequidades de género que se reproducen dentro de este sistema, se encuentra la ausencia e invisibilidad de deliberaciones y proyectos que tengan en cuenta la maternidad para las mujeres, si bien son cada vez más las que asisten a las aulas los esfuerzos por llevar adelante un proyecto académico ponen el tema en el eje de la discusión cuando se trata de tomar decisiones al respecto.

En este sentido los ámbitos universitarios poco se han alejado del modelo de funcionamiento tradicional que reconoce el principio de racionalidad propio del carácter masculino, las mujeres a pesar de ello han logrado continuar avanzando en estos territorios. Sin embargo, la inclusión de ellas no fue de la mano con políticas internas que facilitaran identificar ciertos aspectos propios de sus situaciones particulares en este esquema desigual; las reglamentaciones que pudieran de alguna manera anticipar riesgos y propiciar actividades que sirvan para establecer un entorno favorecedor durante el transcurso de la cursada en general no está presentes.

En Argentina son pocas las casas de altos estudios que han incorporado espontáneamente proyectos de apoyo a estudiantes, ya sea en su reglamento o mediante becas, sala cunas, jardines de infantes, etc. elementos considerados sumamente necesarios ya que durante el cursado la universidad es el lugar en donde más tiempo permanecen. 
Como antecedente de ello, se tiene a la Universidad Nacional de Córdoba (UNC) ${ }^{1}$ que recientemente (año 2012) aprobó un nuevo Régimen para estudiantes trabajadores padres, madres o con personas a cargo que debe ser adaptado en todas sus facultades; en este sentido quienes acrediten dicha condición participarán de ciertos beneficios como: prioridad en la elección del turno de la cursada, el cambio de fechas de las instancias evaluativas, elección de realizar trabajos prácticos de manera individual, consideraciones en cuanto a las ausencias y retrasos en las asistencias entre otras cuestiones. Si bien es evidente que todavía falta un largo camino, ésta reglamentación sienta las bases para pensar en una manera de que a las estudiantes madres se pueda facilitarles el ingreso, cursado, permanencia y egreso de las diferentes facultades.

Recientemente con fecha del 5 de noviembre del 2015 el Consejo Directivo de UNSE aprobó el Régimen de Regularización y Cursada para estudiantes en situación de embarazo, maternidad y paternidad; que viene a poner en cuestión y a favorecer ciertos aspectos de estas singularidades y particularidades por las cuales atraviesan las mujeres durante esta etapas y que necesitan ser visibilizadas para poder llevar adelante medidas concretas que garanticen más espacios de equidad.

\section{Un Panorama Sobre la UNSE}

Desde su creación en el año 1973 la Universidad Nacional de Santiago del Estero (UNSE), procuró responder a las demandas educativas de la región creando diferentes carreras destinadas a posibilitar a los jóvenes el acceso a una educación superior pública y gratuita.

La universidad fue fundada sobre la base de la Facultad de Ingeniería Forestal (1958) primera en su género en el país, pero que pasó a depender académicamente en sus inicios de la Universidad Nacional de Córdoba. Su estructura departamentalizada fue modificada a lo largo del tiempo al igual que su orientación académica. Se puede decir que, su sistema institucional atravesó por tres momentos claves: el primero fue el de su conformación a fines de los años 60 , como respuesta una política regional de creación de universidades relacionadas con el desarrollo regional. El segundo momento, es el del abandono de la estructura departamental e implementación de la estructura por facultades, que tuvo lugar por los años 80 en coincidencia con la normalización democrática de la universidad. Por último, se podría ubicar el tercer momento en los años 90, consistente en la reforma del régimen de elección de las autoridades por el cual el rector y los decanos pasan a ser elegidos por el voto directo de los miembros de la universidad.

Actualmente existen cuatro Facultades: Humanidades Ciencias Sociales y de la Salud, Agronomía y Agroindustrias, Ciencias Exactas y Tecnológicas, Ciencias Forestales y un organismo particular la Escuela de Innovación Educativa.

Según los indicadores de población estudiantil de las universidades

1
http://www.ffyh.unc.edu.ar/sites/default/files/regimen-estudiante-trabajador.pdf
http://www.ffyh.unc.edu.ar/sites/default/files/regimen-estudiante-trabajador.pdf 
públicas $^{2}$, la UNSE representaba para el año 2010 un 1,1\% (15.418) sobre el total nacional (1.316.119); estos datos permiten dimensionar la escaza presencia que tiene en comparación con el resto. Esta situación puede ser el resultado de que si bien en los últimos años se ha acentuado notoriamente la explosión de la matrícula, existe una falta de consolidación estructural que posibilite la coordinación de acciones y el planeamiento estratégico para potenciar los escasos recursos con los que cuenta.

Particularizando a nuestra Universidad, resulta ser uno de los casos en donde la participación de la mujer es muy superior en comparación con los hombres, acentuando los logros que se han venido produciendo en materia educativa y marcando presencia en distintas disciplinas. Al analizar la evolución de los estudiantes inscriptos de la UNSE entre los años 2000-2010 se observa que las mujeres siempre exhiben porcentajes que superan el $60 \%$, constatando las tendencias ascendentes en el estudiantado universitario femenino en distintos países de Latinoamérica. La proporción de varones inscriptos se mantiene sin superar el $40 \%$ y sin variaciones importantes desde el año 2000, encontrando un descenso en el 2009 (25,91\%) que marcará la brecha más importante en relación con la población femenina mostrando una diferencia entre ambos de casi un 50\% (48,18\%).

Estas tendencias tienen un carácter altamente significativo en la formación vocacional de dichas mujeres, ya que dentro de la comunidad académica de esta Universidad serán de un valor importante para determinar las relaciones interpersonales durante el proceso de formación de sus capacidades cognitivas $\mathrm{y}$ de sus identidades profesionales.

\section{El Testimonio de las Estudiantes: Entre Aceptación y Conflicto}

La deliberación sobre si tener o no hijos siempre se encuentra presente en las estudiantes, no pasa lo mismo en el caso de los varones quienes no perciben este asunto al pensar en sus proyectos personales puesto que tradicionalmente las responsabilidades de crianza y cuidado de los niños y niñas recaen sobre ellas ${ }^{4}$. Cuando de hijos se trata, las estudiantes manifiestan en todos los casos haberse planteado seriamente las decisiones que se tomarían al respecto.

Este estudio tuvo como propósito distinguir los resultados encontrados luego del trabajo de campo, para ello se construyó una serie de categorías que

2 Estadísticas Universitarias - Argentina 2010. Secretaría de Políticas Universitarias (SPU) del Ministerio de Educación de La Nación. Directora de la publicación. Lic. Celina Curti. Sitio Oficial: http://repositorio.educacion.gov.ar/

3 Datos obtenidos a partir de un proyecto de investigación que se desarrolla bajo el marco de la Beca Doctoral del CONICET y de cuyos resultados se desprende el presente trabajo, el cual tiene como tema central "Las Relaciones de Género y Campo Académico. El caso de la Universidad Nacional de Santiago del Estero".

4 En su estudio sobre las familias Argentinas Jelin (2012, P.53-57) nos habla del el prototipo de familia nuclear- patriarcal, la división del trabajo se encuentra muy arraigada: el rol de padre- marido- proveedor del hombre adulto es complementado por el rol de esposa-madreama de casa. Según este modelo los hijos e hijas deben ser cuidados por la madre, irán a la escuela, para luego dejar el hogar paterno al establece sus propias familias. 
Imágenes y Perspectivas sobre la Maternidad en las Estudiantes de la

Universidad Nacional de Santiago del Estero

serán útiles para representar y hacer un recorrido por los testimonios de nuestras entrevistadas haciendo hincapié en sus representaciones y percepciones sobre el tema. Estos son algunos de los rasgos encontrados en esta pesquisa.

Por un lado están aquellas estudiantes que 'reproducen el modelo normativo' de socialización concordando con los mandatos sociales tradicionales establecidos y por otro, aquellas que 'han logrado cuestionar este modelo'.

\section{La Construcción de la Identidad Femenina a partir de Su Rol Materno}

En un primer grupo de estudiantes se encuentran aquellas que de alguna manera continúan reproduciendo el patrón de conducta que se les impone socialmente por el hecho de ser mujeres, para ellas existen diversas opiniones en cuanto a su concepción respecto de la maternidad. Se observa que pocas de ellas ponen en duda lo establecido por los modelos de género, en su mayoría concuerdan con los mandatos sociales tradicionales partiendo de que ser madres es necesariamente un hecho biológico.

Las tensiones que pueden presentarse entre el cumplimiento de la vida laboral y las funciones familiares o maternales suelen ser consideradas responsabilidades exclusivas de las mujeres. Los fundamentos ideológicos que sustentan socialmente el cuidado y en especial el cuidado infantil suelen legitimar estos modos de pensar y de actuar en las estudiantes.

El aporte de Cristina ilustra esto:

Considero a la maternidad como una de las experiencias de vida de mayor felicidad, plenitud y crecimiento que un ser pueda experimentar. Un reto que a cada instante se presenta con nuevos desafios para nosotras que trabajamos y estudiamos (Cristina 22 años, estudiante de Sociología)

Muchas de ellas relacionan la maternidad con el sentido de responsabilidad y en alguno de los casos se entiende que es aún mayor que a la de los hombres o parejas, Andrea al respecto dice esto:

La maternidad para mí significa una etapa nueva en la vida de una mujer, en el proceso de su evolución, en la cual desarrolla nuevos sentimientos, emociones y se va descubriendo a sí misma en el día a día de la relación con su hijo, desplegando así todo su potencial como madre. Surgen nuevas percepciones, intereses y preocupaciones y ya hay un nuevo ser que nos necesitará y dependerá de nosotras, al cual hay que garantizarle responsablemente su bienestar (emocional, físico, psíquico, económico, etc.) (Andrea 24 años, 2 hijos, estudiante de Contador Público Nacional)

Tati expresa lo siguiente:

Es maravilloso haber sido madre, llevar a mi hijo en el vientre fueron 
Imágenes y Perspectivas sobre la Maternidad en las Estudiantes de la

Universidad Nacional de Santiago del Estero

soñados... para mi es una de las misiones que se nos ha encargado en nuestra vida y por lo tanto una responsabilidad hermosa de de tener a quien proteger y cuidar, nos completa, nos llena la vida (Tati 21 años, 1 hijo, estudiante de la Lic. en Administración)

El hecho de parir un hijo parece representar un acto de plenitud, existe la sensación de que hasta ese momento se es un ser humano incompleto "mujer es la que es madre" 5 mientras tanto todas se encuentran en proceso de desarrollo. Esta definición de maternidad resultante, esconde un entramado de normas y funciones que se encuentran institucionalizadas en las relaciones dentro de la sociedad y que es percibida como una serie de motivaciones destinadas a mantener una feminidad que solo puede encontrar su existencia vital completa manteniendo la condición de ser madre.

Para ser mujer entonces, se hace necesaria la reproducción voluntaria de determinadas funciones que de acuerdo a las normas pautadas logran definir su ser, el deber primordial es el del cuidado y el servicio hacia los otros y con ello involucra un conjunto de atributos que por lo general están caracterizados por la obediencia y la sumisión. En este esquema, el valor que tiene el otro siempre es mayor que el de ella misma, puesto que solo a partir del reconocimiento de esta otro logra reconocer su propia existencia.

Para Hernando (2012), las mujeres reproducen el modelo preceptivo de socialización por lo cual se le ha transmitido una estructura normativa que prioriza los valores del cuidado, la maternidad y el sostenimiento de los vínculos. De ahí que nuestras entrevistadas a pesar de haberse decidido por llevar adelante roles como los de estudiantes y a veces también como trabajadoras sigan considerando la maternidad como una forma de reafirmar su identidad de mujeres y por lo cual buscan irrenunciablemente mantener el conjunto de las relaciones vinculadas al ámbito familiar y doméstico para sentirse completas.

\section{Avances Socio-Históricos y su Correlato en los Nuevos Modos de Pensar la Maternidad}

Se entiende que el proceso de feminización universitaria es parte de un fenómeno relacional, que como lo plantea (GRAÑA, 2008) toma varios elementos de la dinámica social; uno que involucra la manera en que se han transformado las relaciones de género y por otro lado el contexto sociohistórico como marco de una serie de cambios que se dieron durante el siglo XX.

Aquellas estudiantes que han logrado 'cuestionar y reflexionar respecto de los mitos en torno a la maternidad', por lo general; han sido parte de los efectos producidos por estos cambios sociales que han logrado modificar una serie de comportamientos a partir del reconocimiento y la percepción de sus derechos, así como también la posibilidad de decidir sobre sus proyectos de vida.

5 Para Lagarde (2003, p. 363) Todas las mujeres por el simple hecho de serlo son madres y esposas, la historia de la humanidad las ha conformado ya desde su nacimiento como madres y esposas; ambas funciones constituyen esferas vitales que organizan y conforman los modos de vida femeninos. 
Imágenes y Perspectivas sobre la Maternidad en las Estudiantes de la

Universidad Nacional de Santiago del Estero

En este escenario, la búsqueda por alcanzar ser profesionales para muchas estudiantes se pone en primer plano; la decisión sobre ser madres para muchas se encuentra escasamente presente. La maternidad es percibida como un 'obstáculo' para lograr ciertos propósitos sobre todo si se encuentran en pareja, las negociaciones comienzan a hacerse presentes en torno a una planificación familiar acorde con las metas personales.

Mariana dice al respecto:

Yo creo que el ejercicio de la maternidad te hace muy dependiente, muchos de los espacios en donde una se desarrolla debe generarlos y buscarlos y eso nos cuesta mucho.... por eso creo que en la práctica tal vez tenga más oportunidades la mujer sin hijos, lo mejor sería para mi seria esperar un poco" (Mariana 20 años, estudiante de la Lic. en Obstetricia)

Para aquellas universitarias que aún no han tenido hijos, la percepción sobre su autonomía personal, el uso del tiempo libre y la valoración de ciertas libertades que les proporciona el no tener a cargo un niño es altamente significativa. Hay quienes directamente ni siquiera han pensado en dicha posibilidad o al menos no lo tienen presente como algo por considerar. Surgen entonces así nuevos modos de concebir la maternidad, las mujeres emprenden una carrera universitaria no sólo en busca de obtener un título; si no también tratando de conquistar la posibilidad de una emancipación de su propio género sobre aquellos mandatos sociales que históricamente las han marcado.

mmmmm no sé, la verdad que ahora que me lo preguntas estoy pensando. Yo no sé si quiero tener hijos, siempre he tenido la idea de vivir sola y aprovechar al máximo mi carrera y mi trabajo en eso pongo mucho esfuerzo y no quisiera arruinarlo la verdad... tengo miles de cosas por hacer entre ellas viajar y conocer otros lugares. Quizás a muchos les parezca egoísta pero he decidido vivir la vida a mi modo (Daniela 22 años, estudiante de Sociología)

Se observa que en estos casos las mujeres han logrado repensar los modos en que estructuran sus vidas a partir de la libre disposición que tienen sobre sus cuerpos, por lo que las jóvenes estudiantes asumen comportamientos que suelen estar en desacuerdo con el imaginario social que se tiene sobre ella y sobre su función maternal.

Para quienes tienen una pareja o se encuentran casadas, los planes y las decisiones por lo general sueles ser más dificultosas. Sin embargo, recientemente se ha experimentando como las relaciones de género fueron tomado diferentes matices, los roles que eran tradicionalmente desempeñados por hombres y mujeres han ido cambiando paulatinamente y aunque estas transformaciones no se han dado de manera homogénea en las diferentes sociedades y pese a que los varones continúan siendo preponderantes en los distintos ámbitos de la vida social, las mujeres han logrado incrementar sus niveles de negociación.

'Planificar, acordar y hacer negociaciones' al interior de la pareja se 
Imágenes y Perspectivas sobre la Maternidad en las Estudiantes de la

Universidad Nacional de Santiago del Estero

convierte en algo crucial sobre todo en aquellas estudiantes que han sido madres o piensan en serlo. La llegada de un nuevo integrante a la familia suele cambiarlo todo y comienza un nuevo reto para las mujeres: lograr que el proyecto académico no se desvanezca pese a las dificultades y los obstáculos que suelen presentarse.

Es entonces en donde la a figura del padre o de la familia pasan a un primer plano. El cuidado y la crianza del los niños es uno de los aspectos más serios para los cuales se destina tiempo en pensar y programar, sobre todo si se quiere continuar estudiando. La ayuda por parte de los parientes más cercanos, sobre todo la presencia de las madres constituye un apoyo principal para ellas.

No sé qué haría sin mi mamá, ella me ayuda mucho y me alienta para que siga estudiando... por lo general el gordo se queda con ella cuando yo voy a cursar o rendir... le preparo todo antes de irme hasta lo que va a comer. Sé que mi mami lo cuida bien pero a veces siento mucha pena de dejarlo, pienso que me necesita a mí también (Abigail 23 años, 1 hijo, estudiante de Contador Público Nacional)

Aquellas que han logrado de alguna manera articular estrategias para sostener su proyecto universitario, están en la búsqueda constante del equilibrio entre las responsabilidades domésticas y las académicas lo cual requiere de una planificada organización. El manejo del tiempo frecuentemente se acomoda entre las necesidades de los niños y los horarios de clase, poco espacio queda para la recreación o el tiempo libre de uso personal, estas actividades quedan relegadas.

Así relata su experiencia Ana:

Una mujer madre durante la carrera se debe organizar $y$ compatibilizar su tarea profesional y el resto de su vida. Por ahi el tema esta en que hay que plantear y acomodar el tema de los horarios laborales. Con hijos es más dificil, porque por ahi se enferman, tienen sus horarios de jardín, cumpleaños, las reuniones, sus actividades extras y una quiere estar presente en todo, aparte del trabajo de una, pero todo va tomando forma" (Ana 24 años, 1 hijo, estudiante de la Lic. en Educación para la Salud)

Así como Ana, cada vez son más las mujeres madres que ingresan y permanecen en la universidad. Sin embargo, las estudiantes suelen manifestar que si bien tratan de organizarse de la mejor manera aún no logran encontrar el equilibrio. Frecuentemente suelen llegar extenuadas al final de la jornada, las tensiones que se presentan al desempeñar roles contradictorios comienzan a manifestarse y aunque logran lidiar con ellas rompiendo con los estereotipos siempre están envueltas en una constante negociación y renegociación con esas construcciones subjetivas que delimitan su papel como mujer-madre.

Si bien estas construcciones mencionadas en parte dependen de un costado personal y familiar, también la exigencia de cumplir con aquellas expectativas tradicionales de una maternidad responsable es el resultado de un plan de domesticación social, cultural y político hacia las mujeres que ha delimitado su 
Imágenes y Perspectivas sobre la Maternidad en las Estudiantes de la

Universidad Nacional de Santiago del Estero

espacio al hogar y al deseo de ser madres tal como lo plantea Nari (2004).

Romper con este disciplinamiento constituye una constante para las mujeres que estudian, pero gracias a esa constancia es que se ha logrado hasta ahora favorecer la promoción y emancipación de las mujeres en muchos aspectos. Uno de esos aspectos está relacionado con la transformación de los roles y las negociaciones que se producen al interior de la pareja respecto del manejo de las cuestiones domésticas.

Si bien es poco frecuente, la presencia activa del padre en la dinámica familiar es requerida cada vez más por parte de las mujeres. Así lo narra Beatriz: "Si... yo tengo el constante apoyo de mi marido. Tenemos tiempos divididos del cuidado de nuestras hijas" (Beatriz 25, 2 hijos, estudiante de Sociología)

En general los varones participan poco de las actividades domésticas, organizar la casa, hacer la limpieza, cocinar, lavar, cuidar los niños todas son "tareas marcadas por el género, son no masculinas" por lo cual lograr que realicen voluntariamente alguna de ellas se hace difícil. En la pareja es frecuente un juego de arreglos y mediaciones, y aunque algunas de las estudiantes logran alcanzar un mayor grado de compromiso por parte de sus cónyuges suelen hacer referencia a ello como una ayuda o colaboración no como una responsabilidad por parte de estos.

Como lo afirma Wainerman (2007, p. 197) las transformaciones sociofamiliares fueron estableciendo nuevos esquemas de hogares en donde la participación del varón es más activa en algunas ocasiones, sin embargo la situación de las mujeres madres y en este caso estudiantes es mucho más compleja que en otros tiempos.

Es visible el logro de cierta autonomía, pero por otro lado aparecen una serie de obstáculos para los cuales se hace necesario desplegar una batería de recursos para mantener la organización de la casa; si bien algunas de las tareas pueden ser delegadas al cónyuge, familiar u otra persona de confianza eso no las exime de la responsabilidad que se les asigna por su ejecución, lo que significa que tienen que pensar y deliberar sobre el modo en que se realizarán esas tareas y para ello invierte su energía y ocupa también su mente.

\section{Algunas Consideraciones Finales}

Es notable que a pesar de tratarse de mujeres jóvenes que han decidido estudiar una carrera y denotan cierta autonomía e independencia personal, pocas de ellas logran cuestionar los parámetros establecidos socialmente para el ejercicio de la maternidad más bien se trata de mujeres que concuerdan con las expectativas impuestas socialmente. Las diferencias que se encuentran están presentes y se visibilizan principalmente entre aquellas que no han sido madres y que por lo general remarcan ciertos aspectos como: los beneficios de retrasar la maternidad para concretar sus proyectos académicos e individuales, el deslindarse de una responsabilidad que tradicionalmente recae sobre las mujeres, los acuerdos y negociaciones que se plantearían a nivel pareja si existiera la posibilidad de un hijo o simplemente la decisión personal de no ser madres o ni siquiera pensar en ello.

Aquellas que ya han sido madres presentan una visión diferenciada de la

Noelia Noemi Aranda 
cuestión, de las entrevistas realizadas se ha podido deducir que con el tiempo se fueron favoreciendo el desarrollo de nuevos modelos de maternidad en donde la dinámica intradoméstica suele variar, la corresponsabilidad paterna en la crianza de los niños puede estar presente. En ciertos casos, el rol del varón y de las redes familiares conjuntamente con los lazos de amistad juegan un papel importante, las horas de cuidado y dedicación a los hijos se reducen y se acomodan a las cargas de estudio o estudio y trabajo ya sea el caso.

Por último, no se puede dejar de hacer referencia sobre la parte que le corresponde a la Universidad como institución, como premisa se hace necesario generar espacios para pensar sobre las condiciones y situaciones por las cuales atraviesan las mujeres durante el cursado de una carrera, esto resulta fundamental para cambiar las relaciones desiguales que se producen entre los sujetos que participan allí. Este tipo de acciones promoverán no solamente el debate al respecto, sino que permitirán favorecer la creación de medidas concretas que garanticen el ingreso y la permanencia de todas las personas desde una perspectiva de equidad.

\section{Referências}

GRAÑA, François. El asalto de las mujeres a las carreras universitarias 'masculinas': cambio y continuidad en la discriminación de género. Revista PRAXIS Educativa, n. 12, p. 77 - 86, 2008.

HERNANDO, Almudena. La fantasía de la individualidad. Sobre la construcción socio-histórica del sujeto moderno. España; Ediciones Kats, 2012.

JELIN, Elizabeth. La familia en Argentina: Trayectorias históricas y realidades contemporáneas. En: ESQUIVEL, Valeria; FAUR Eleonor; JELIN Elizabeth (Edits.). Las lógicas del cuidado infantil. Entre las familias, el estado y el mercado. Buenos Aires. IDES, 2012, p. 45 - 71.

LAGARDE DE LOS RIOS, Marcela. Los cautiverios de las mujeres, madresposas, monjas, putas, presas y locas. Coyoacán México DF: Universidad Nacional Autónoma de México. Ciudad Universitaria, 2003.

LAGARDE DE LOS RIOS, Marcela. Sinergia por nuestros Derecho Humanos en España, Guatemala y México. En: LAGARDE DE LOS RIOS, Marcela y VALCÁRCEL, Amelia (Coords.) Feminismo, género e igualdad. Madrid: Pensamiento Iberoamericano / Fundación Carolina, 2008, p. 111 148.

MAFFIA, Diana. Carrera de obstáculos: las mujeres en ciencia y tecnología. RAGCyT, Instituto Interdisciplinario de Estudios de Género. La Habana. Pág. 1-7. 2008. Disponível em: $<$ http://www.ragcyt.org.ar/descargas/5202_doc.pdf $>$. Acesso em 9 de Junho de 2017. 
Imágenes y Perspectivas sobre la Maternidad en las Estudiantes de la

Universidad Nacional de Santiago del Estero

NARI, Marcela. Políticas de Maternidad y Maternalismo Político. Buenos Aires, 1890- 1940. Buenos Aires: Biblos, 2004.

VARGAS VALENTE, Virginia. Feminismos en América Latina. Su aporte a la política y a la democracia. Lima: Universidad Nacional Mayor de San Marcos-Flora Tristán de la Facultad de Ciencias Sociales, 2008.

VALLADARES, Blanca. Revisión teórica sobre los mitos de la maternidad. Revista de Ciencias Sociales, n. 65, p. $67-74,1994$.

VARELA, Nuria. Feminismo para principiantes. Barcelona: Ediciones, 2005.

WAINERMAN, Catalina. Conyugalidad y Paternidad ¿Una revolución estancada?. En: GUTIÉRREZ, María Alicia (Compiladora). Género, Familias y Trabajo: rupturas y continuidades. Desafíos para la investigación política. Buenos Aires: CLACSO, 2007, p. 179 - 222. 